\title{
Wadsworth Named Honorary Member of ASM International
}

๑) Springer Science+Business Media, LLC, part of Springer Nature and ASM International 2018

ASM International was proud to name Dr. Jeffrey Wadsworth, FASM, as the 2017 recipient of Honorary Membership in the Society, for leadership of the world's largest independent research and development organization, for support of national technology and materials society initiatives, and for pioneering research on superelasticity of alloys.

Honorary Membership in the Society was established in 1919. It recognizes distinguished service to the materials science and engineering profession, service in areas of ASM strategic plan/initiatives 90 and to the progress of mankind. It is among the most prestigious awards of the Society. Consequently, it is expected that all nominees will be truly outstanding individuals who have significantly furthered the purposes of the Society and, through distinguished service to the materials science and engineering profession, the progress of mankind.

Dr. Wadsworth has distinguished himself in all of those areas over the years through his work at some of the largest research laboratories across the country, beginning at Stanford University, followed by Lockheed Missiles and Space Company, Lawrence Livermore National Laboratory, and the Oak Ridge National Laboratory. He has also worked with ASM as a member of the Metallography, Microstructure, and Analysis Editorial Board since the journal's inception in 2012.

At the end of 2017, Wadsworth retired from Battelle Memorial Institute where had he served as CEO since 2009. Battelle is the world's largest nonprofit research and development organization, executing approximately $\$ 5.5$ billion of work annually and employing approximately 22,500 people. Prior to that, he led Battelle's Global Laboratory Operations business, where he oversaw the management or co-management of six national laboratories of the U.S.
Department of Energy and the U.S. Department of Homeland Security's National Bio-Defense Analysis and Countermeasures Center.

Congratulations to Dr. Wadsworth from his fellow members of the Metallography, Microstructure, and Analysis Editorial Board, as well as the International Metallographic Society Board of Directors.

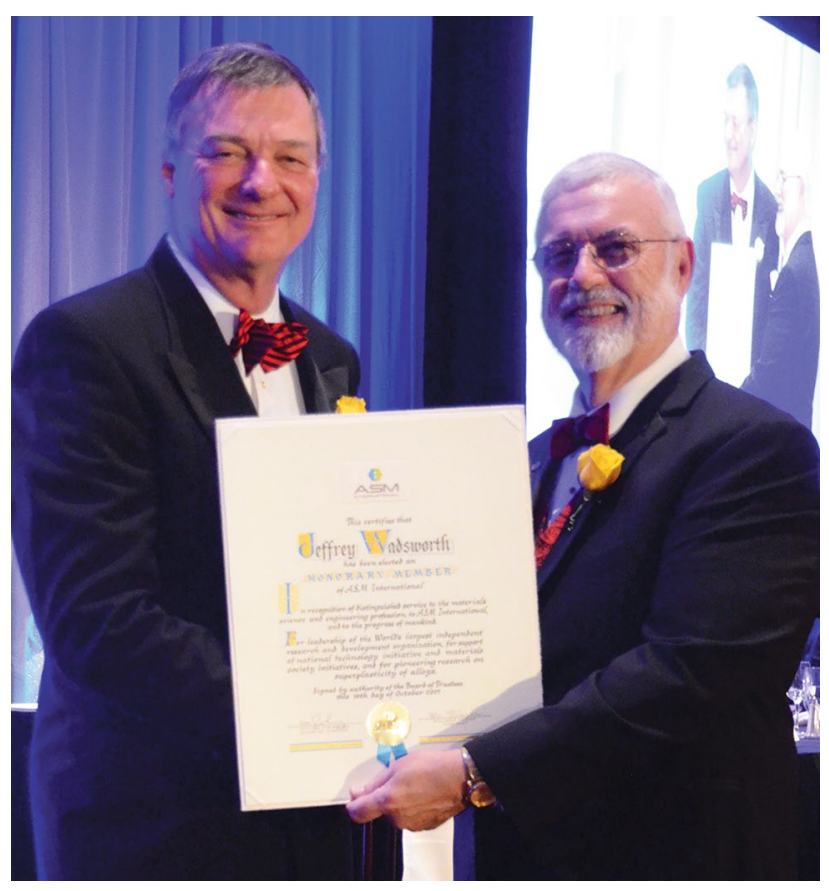

Dr. Jeffrey Wadsworth receives his Honorary Membership certificate from ASM President William Frazier 